\title{
Synthesis and characterization of nano-activated carbon from el maghara coal, Sinai, Egypt to be utilized for wastewater Purification
}

\author{
M. F. Elkady ${ }^{1,2,{ }^{*}, \text { M. M. Hussein }}{ }^{3}$, M. M. Salama ${ }^{3}$ \\ ${ }^{1}$ Chemical and Petrochemical Engineering Department, Egypt-Japan University of Science and Technology, New Borg El-Arab City, \\ Alexandria, Egypt \\ ${ }^{2}$ Fabrication Technology Department, Advanced Technology and New Materials and Research Institute (ATNMRI), City of Scientific Research \\ and Technological Applications, Alexandria, Egypt \\ ${ }^{3}$ Chemical Engineering Department, Faculty of Engineering, Alexandria, Egypt
}

Email address:

maroelkady@yahoo.com (M. F. Elkady)

\section{To cite this article:}

M. F. Elkady, M. M. Hussein, M. M. Salama. Synthesis and Characterization of Nano-Activated Carbon from El Maghara Coal, Sinai, Egypt to be Utilized for Wastewater Purification. American Journal of Applied Chemistry. Special Issue: Nano-technology for Environmental Aspects. Vol. 3, No. 3-1, 2015, pp. 1-7. doi: 10.11648/j.ajac.s.2015030301.11

\begin{abstract}
This study targeted to evaluate the availability of extraction the nano-activated carbon from el maghara coal that represents as Jurassic coal deposits in the Maghara area, Sinai, Egypt to be utilized as adsorbent material for methyl orange dye decontamination from polluted wastewater. Nano-activated carbon was prepared through the alkaline and acidic activation of el maghara coal with potassium hydroxide and phosphoric acid respectively at different conditions such as activation temperature, activation time and activating agent/ carbon ratio. The maximum removal for methyl orange with the extracted nano-activated carbon was recorded to be $90 \%$. This efficient nano-activated carbon was synthesized through the reaction of el maghara coal with potassium hydroxide with 1:2 weight ratios for 90 minutes. Then the yielded powder material was carbonized at $600^{\circ} \mathrm{C}$ for 90 minutes. The physical and chemical characteristics of raw coal and the most efficient extracted nano-activated carbon material were examined using different techniques such as scanning electron microscopic and infrared spectroscopy analysis. The different factors affecting the methyl orange treatment process onto the most efficient prepared material will be optimized using the batch technique. The equilibrium time for dye sorption process onto the prepared nano-activated carbon was established at $120 \mathrm{~min}$. the improvement at both the agitation speed and the material dosage has positive effect on the dye sorption process. The maghara coal was establish to be suitable resource for Nano-ctivated carbon extraction as an adsorbent after alkaline and thermal activation of the raw el maghara coal for the removal of methyl orange dye from polluted industrial wastewater.
\end{abstract}

Keywords: Nano-Activated Carbon, Dyes Adsorption, Low Cost Adsorbents, Wastewater Treatment

\section{Introduction}

Dyes are widely used in industries such as textiles, rubber, paper, plastics, cosmetics etc. A large variety of dyestuffs is available. They can be conveniently classified according to their type, which reflects their macroscopic behavior(acid, basic, reactive, direct, disperse, sulphur and metallic dyes) and also according to their prevailing properties (porosity, surface area).Disposal of this colored water from dyeing industries into receiving water generally may be toxic to aquatic life. The dyes upset the biological activity in water bodies. They also pose a problem because they may be mutagenic and carcinogenic and can cause severe damage to human beings, such as dysfunction of kidney, reproductive system, liver, brain and central nervous system [1,2].Treatment of dye-based effluents is considered to be most challenging in the environmental fraternity and the industries, the recent stringent regulations compound the problem further .

Respecting to the large degree of organics present in these molecules and the stability of modern dyes, conventional biological treatment methods are ineffective for their removal $[3,4]$. This led to the study of other effective methods. 
Adsorption is major technique that used for dyes removal from wastewater [5]. It has many advantages over several other conventional treatment methods for wastewater treatment. These include (i) less land area , (ii) lower sensitivity to diurnal variation, (iii) not getting affected by toxic chemicals, (iv) greater flexibility in the design and operation and (v) superior removal of organic contaminants [6].

Activated carbon is the most widely used adsorbent for this purpose because of its extended surface area, micro porous structure, high adsorption capacity and high degree of surface reactivity. However, commercially available activated carbons are very expensive [7-9]. Therefore, studies are now focusing on new natural adsorbents with low cost and local availability, such as chitosan, bentonite, zeolite, clay minerals, olive mill residue, flay ashes, coal, rice husk, waste tea leaves, peanut hull pellets and bio sorbents. This study targeted to evaluate the availability for activated carbon extraction from el maghara coal to be utilized as adsorbent material for methyl orange dye removal. The synthesis of high performance activated carbons is feasible using maize talks and $\mathrm{KOH}$ activation. Note that recent studies have showed that it is possible to use natural wastes (e.g., egg shell residues) to produce alternative and low cost activating agents for improving the adsorption properties of activated carbons for heavy metal removal [10]. Analysis of coal rank parameters indicated that the maghara coal can be classified as medium volatile bituminous coal [11].The optimum conditions of chemical activation for nano-activated carbon production and the best condition for treatment of the produced activated carbon were evaluated.

\section{Experimental}

\subsection{Chemical and Thermal Modification of El Maghara Coal}

El Maghara coal was used as the starting raw material for nano-activated carbon production. The proximate and ultimate analyses of the raw coal are shown in table 1. Unless otherwise specified, the particle sizes of the coal used for carbon preparation were within a range of $0.4-0.6 \mathrm{~mm}$.

Table 1. The ultimate and proximate analysis of Maghara coal [12]

\begin{tabular}{ll}
\hline Parameters & Values $(\mathbf{\%})$ \\
\hline -Proximate analysis & \\
Ash & 4.12 \\
Moisture & 2.65 \\
Volatile & 50.6 \\
Fixed carbon & 40.00 \\
-Ultimate analysis & \\
Carbon & 71.44 \\
Hydrogen & 6.62 \\
Oxygen (by diff) & 9.1 \\
Nitrogen & 2.27 \\
Sulphur & 3.8 \\
\hline
\end{tabular}

Chemical activation of el Maghara coal was performed using potassium hydroxide and phosphoric acid as the reagents. The activation process was initiated in a $250-\mathrm{ml}$ glass-stopper flask through mixing $2 \mathrm{~g}$ of the as-received coal with a solution consisting of $50 \mathrm{~g}$ of water and $4 \mathrm{~g}$ of a chemical reagent. The flask was immersed in a constant-temperature shaker bath, with a shaker speed of 150 $\mathrm{rpm}$. The mixing was performed at $80^{\circ} \mathrm{C}$ and lasted for $2 \mathrm{~h}$. After mixing, the coal slurry was subjected to vacuum drying at $110{ }^{\circ} \mathrm{C}$ for $8 \mathrm{~h}$. The resulting chemical loaded samples were then carbonized in a horizontal cylindrical furnace. Carbonization was carried out by heating the samples at $30{ }^{\circ} \mathrm{C}$ min from room temperature to carbonization temperatures in a range of $400-700{ }^{\circ} \mathrm{C}$, followed by holding the samples at the carbonization temperature for 90 minutes before cooling under $\mathrm{N}_{2}$.

After cooling the carbonized products that have been treated with $\mathrm{KOH}$ and $\mathrm{H} 3 \mathrm{PO} 4$ were subjected to washing by stirring with $250 \mathrm{ml}$ of $0.5 \mathrm{~N} \mathrm{HCl}$ solutions at $80{ }^{\circ} \mathrm{C}$ for $30 \mathrm{~min}$, followed by filtration for powder separation. The acid-washed samples were then leached by mixing with $250 \mathrm{ml}$ of distilled water at $80^{\circ} \mathrm{C}$ for several times until the $\mathrm{pH}$ value of the water-carbon mixture was between $6-7$. The leached products were then dried by vacuum at $110^{\circ} \mathrm{C}$ for $8 \mathrm{~h}$ to give the nano-activated carbon products. For the samples treated with $\mathrm{H}_{3} \mathrm{PO}_{4}$, the washed solution was alkalized with $\mathrm{NaOH}$ instead of the $\mathrm{HCl}$ and the samples were leached by distilled water to reach a $\mathrm{pH}$ value between $6-7$.

\subsection{Characterization of Synthesized Nano-Activated Carbon}

In order to have a better understanding the difference in the properties between the raw el Maghara coal and the prepared nano-activated carbon, different physico-chemical characterization techniques was examined. The Fourier Transform Infrared spectrum (FTIR - 8400 S Shimadzu, Japan) was used in order to determine the chemical structural change on the Maghara coal sample after the chemical and thermal activation. Furthermore, the Scanning Electron Microscope (SEM-JEOL JSM6360 LA, Japan) was used to study the structural features of the carbon surface. The crystalline structure of the prepared materials was established using XRD (X-ray powder diffractometry).

\subsection{Batch Technique for Dye Decolonization Using the Prepared Materials}

In order to screen the efficiency of the different prepared samples after the chemical and thermal modifications, the batch technique was utilized for testing the material performance for dye decontamination. The experiments were performed through mixing $0.25 \mathrm{~g}$ from the prepared material with $50 \mathrm{ml}$ from M.O (methyl orange) solution in the concentration of $100 \mathrm{ppm}$ in closed bottles. The mixture was stirred at room temperature $(25 \pm 2){ }^{0} \mathrm{C}$ for 2 hours at $200 \mathrm{rpm}$ as determined from the pre-performed kinetic tests. The percentage removal of dye was calculated using the following relationship:

Percentage removal $\%=\{(\mathrm{Ci}-\mathrm{Cf}) / \mathrm{Ci}\} * 100$ 
Where, $\mathrm{Ci}=$ initial dye concentration, $\mathrm{Cf}=$ final dye concentration.

The different factors affecting at the batch process for dye decontamination using the most efficient prepared material will be tested such as contact time, dye concentration and material dosage.

\section{Results and Discussion}

Respecting to the preparation of nano-activated carbon from Maghara coal through the coal activation principally consists of two consecutive steps which are impregnation of a chemical reagent followed by carbonization. The experimental results are discussed separately as follows.

\subsection{Influence of the Chemical Modification Process onto the Dye Decontamination Efficiency of the Prepared Materials}

The influence of both the reactants weight ratios and the carbonization temperatures either for alkaline or acidic treatment will be tested onto the performance of the produced materials for methyl orange dye decolorization process.

\subsubsection{Effect of the Reactant Weight Ratios onto the Material Performance}

The influence of the different alkaline and acidic reactants ratio using potassium hydroxide and phosphoric acid respectively on the percentage dye removal of the produced materials was monitored to determine the optimum reactant ratios with the type of the chemical reaction. For the acidic chemical modification, Fig. 1 investigates that the increase at both the reaction time and the reactant weight ratios has positive effects on the dye decolorization efficiency of the produced materials.

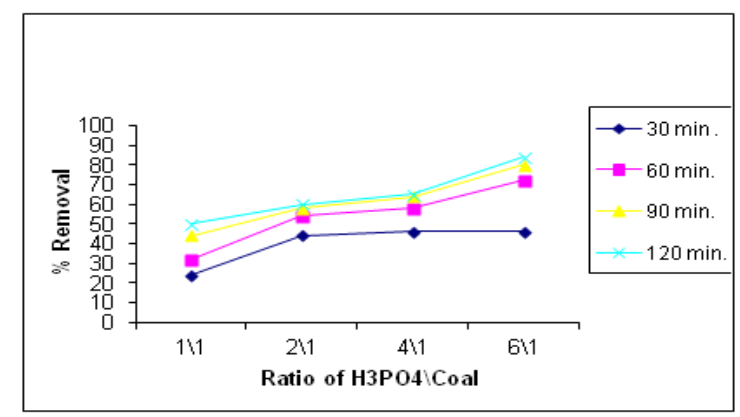

Figure 1. Effect of Reagent /coal ratio on methyl orange removal onto the different prepared materials after the treatment with phosphoric acid at 600 ${ }^{0} \mathrm{C}$.

However, this improvement at the dye decolorization efficiency of the prepared materials with the increase at both the reaction time and the reactant weight ratios was scaled up in the case of the alkaline treatment. It was evident from fig. 2 that the methyl orange decolorization process improves as the potassium hydroxide to raw coal ratio increases especially for the alkaline treatment that takes place for short reaction periods. As the alkaline treatment period increases above90min, there is no significant improvement at the dye treatment process with the increase at the reactant ratio. So, $2 / 1$ weight ratio from the raw coal to the potassium hydroxide was recorded as the optimum reactant ratio at the reaction time of $90 \mathrm{~min}$.

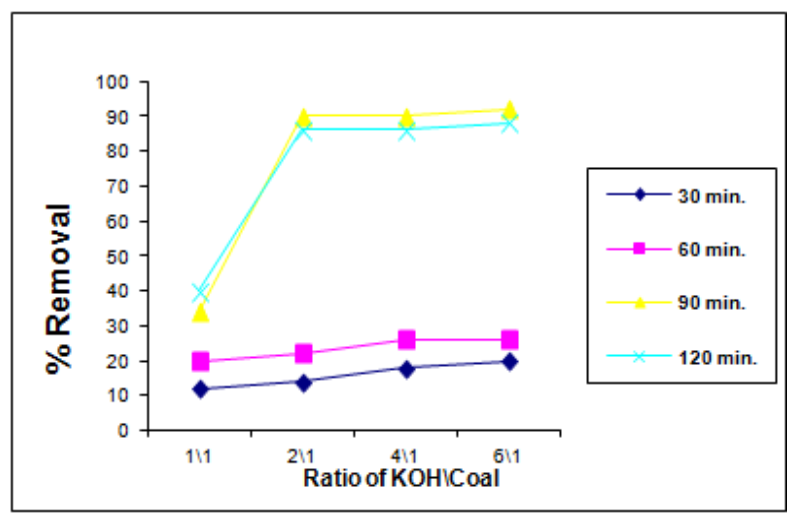

(a)

(b)

(c)

Figure 2. Effect of Reagent /coal ratio on methyl orange removal onto the different prepared materials after the treatment with $\mathrm{KOH}$ at $600{ }^{\circ} \mathrm{C}$.

\subsubsection{Effect of the Carbonization Temperature onto the Material Performance}

As an attempt to enhance the performance of the different prepared materials produced from both the alkaline and the acidic chemical modification processes, the carbonization temperature of these materials will be varied in the range $\left(400-600^{\circ} \mathrm{C}\right)$ to determine the most proper carbonization temperature that yield the highly efficient material for dye decolorization. Regarding to the acidic treatment, it was indicated from Fig. 3 that there is a slight improvement at the dye decolorization from $30 \%$ to $70 \%$ as the carbonization temperature increased from 400 to $700{ }^{\circ} \mathrm{C}$ at the high reactant ratios from the raw coal to the phosphoric acid.

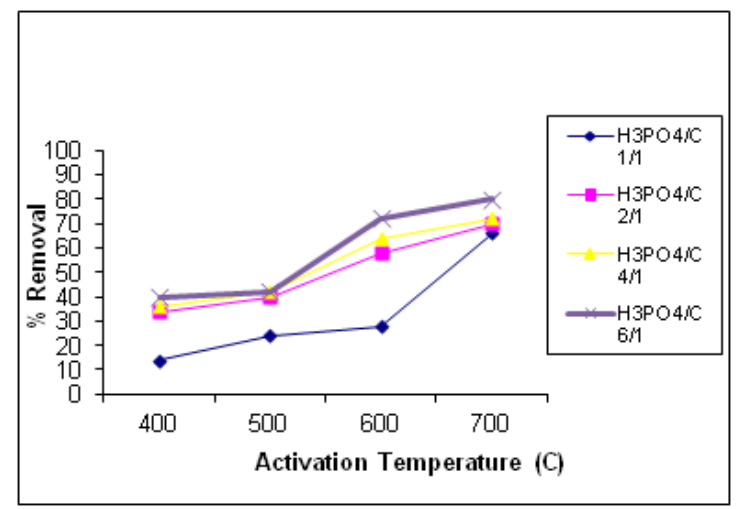

Figure 3. Effect of carbonization temperature on methyl orange removal onto the different prepared materials after the treatment with phosphoric acid

For the equivalent ratios from the raw coal to the phosphoric acid (1:1), the dye percentage decolorization increased from 10 to $40 \%$. This improvement at the dye decolorization is comparatively low compared with the alkaline activation process. It was indicated from Fig. 4 that the increment at the carbonization temperature from 400 to $700{ }^{\circ} \mathrm{C}$ increases the percentage dye removal from $5 \%$ to 
around $90 \%$ for the high alkaline to raw cool ratio above $1: 1$. So, the predetermined optimum reactant ratio of $2 / 1$ weight ratio from the raw coal to the potassium hydroxide was confirmed as the most efficient alkaline activation ratio. Moreover, the optimum carbonization temperature was detected at $600^{\circ} \mathrm{C}$ for the alkaline potassium treatment [13].

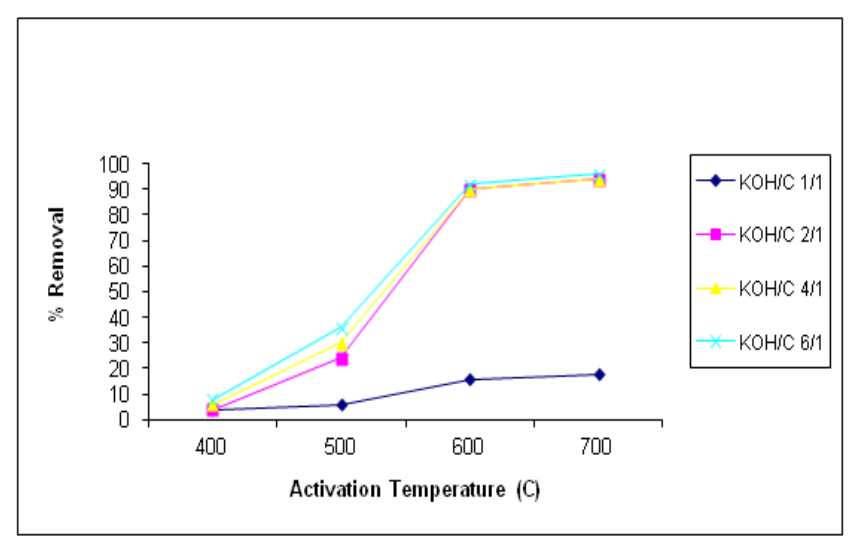

Figure 4. Effect of carbonization temperature on methyl orange removal onto the different prepared materials after the treatment with potassium hydroxide

\subsection{Characterization of the Most Efficient Prepared Material}

The crystalline, chemical and morphological structures of the most efficient prepared material that recorded the highest dye decontamination will be examined to be compared with the raw Maghara cool using XRD, FTIR and SEM. Firstly the chemical structures of the raw cool was compared with the efficient prepared sample using FTIR, Fig. $(5 \mathrm{a}, \mathrm{b})$ shows the FTIR spectra of the two samples. It was indicated that the raw coal sample exhibited noticeable IR bands below 1700 $\mathrm{cm}^{-1}$ and between 2750 and $3250 \mathrm{~cm}^{-1}$. The broad band represented at approximately $1200 \mathrm{~cm}^{-1}$ may due to the overlapping of $\mathrm{C}-\mathrm{O}-\mathrm{C}$ stretching, $\mathrm{C}-\mathrm{O}$ stretching and $\mathrm{O}-\mathrm{H}$ bending modes of alcoholic, phenolic and carboxylic groups. The band at $1600 \mathrm{~cm}^{-1}$ is assigned to $\mathrm{C}=\mathrm{C}$ stretching conjugated with another $\mathrm{C}=\mathrm{C}$ bond, an aromatic nucleus, or a $\mathrm{C}=\mathrm{O}$ bond. It has been reported that the $\mathrm{C}=\mathrm{C}$ stretching frequently occurs at approximately $1600 \mathrm{~cm}^{-1}$ for carbonaceous materials .The bands at around $2900 \mathrm{~cm}^{-1}$ are assigned to alkyl groups such as $-\mathrm{CH} 3,=\mathrm{CH} 2$ and $-\mathrm{CH} 2 \mathrm{CH} 3$. The weak band at around $3500 \mathrm{~cm}^{-1}$ can assigned to the $\mathrm{O}-\mathrm{H}$ stretching vibration mode of hydroxyl functional groups. These surface functional groups can serve as active sites where chemical transformations occur via surface reactions. These results illustrated that the most efficient prepared material represented as activated carbon [14].

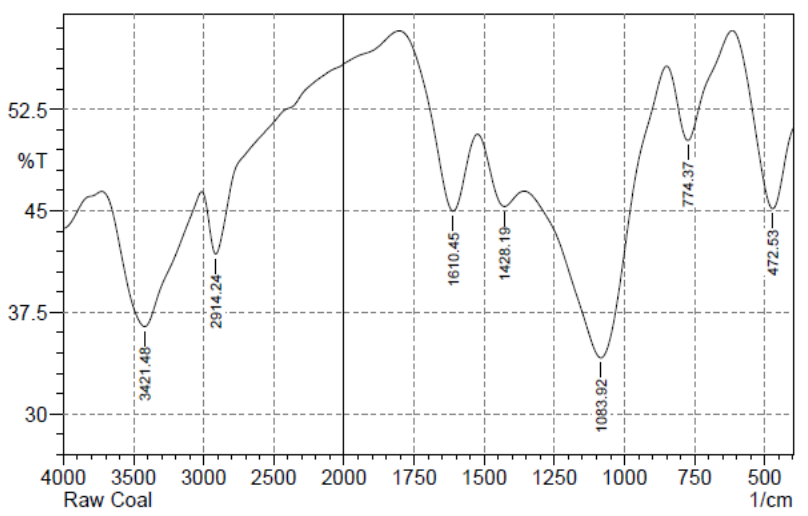

(A)

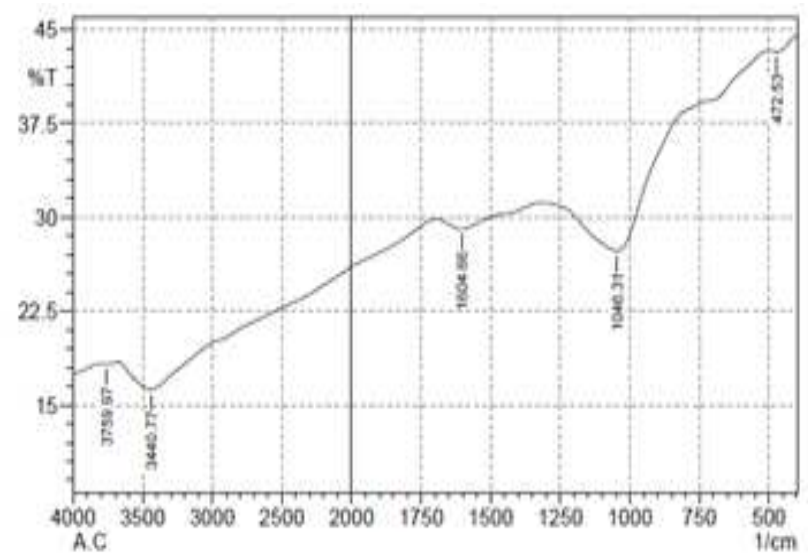

(B)

Figure 5. FTIR spectrums of raw maghara cool (A) and the prepared activated carbon (B)

In order to confirm its crystalline structure, the XRD spectrum of the prepared sample was compared with the raw cool and investigated at Fig. $(6 a, b)$.

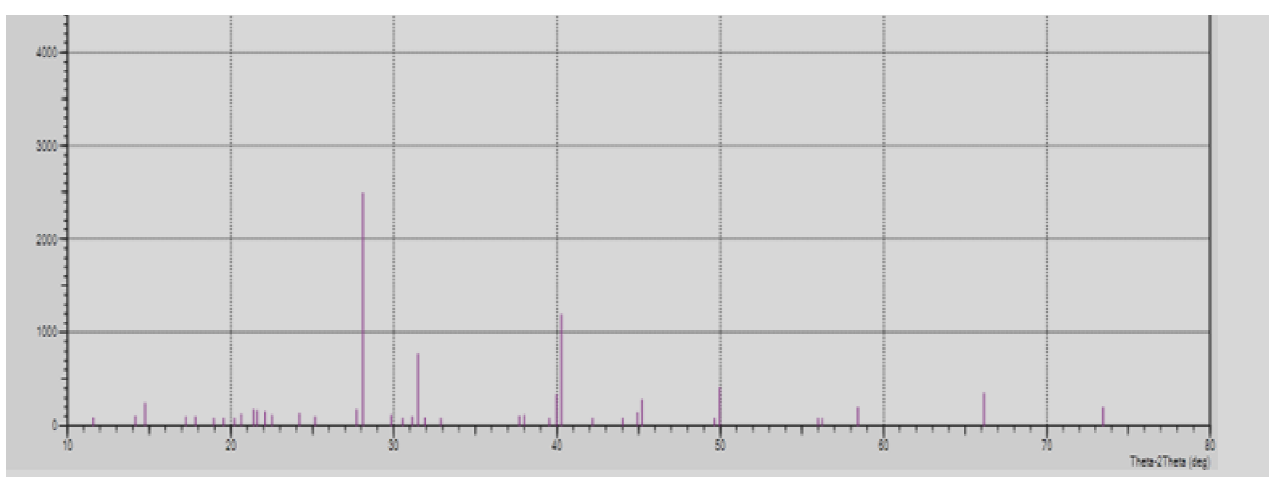

(A) 


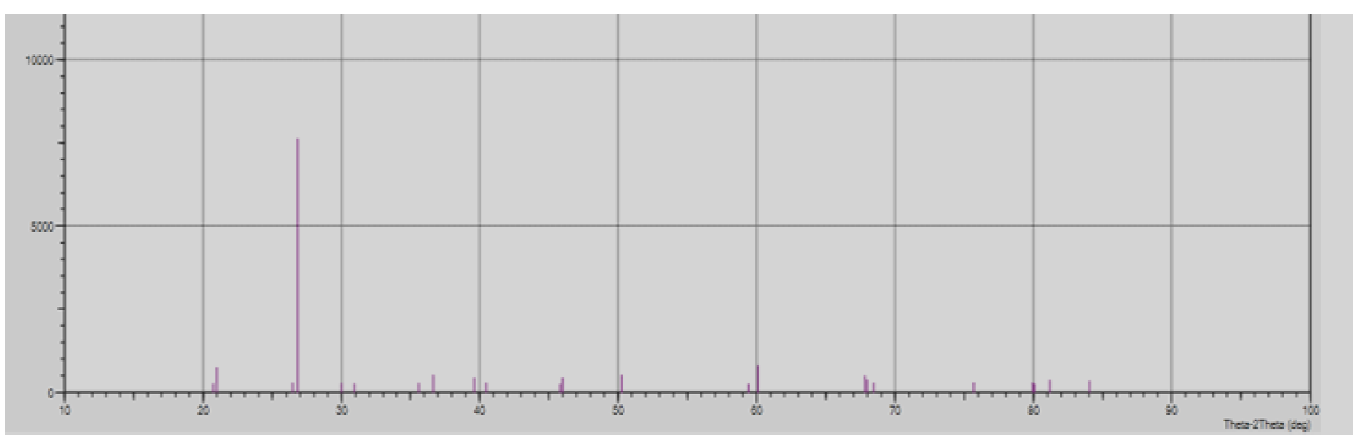

(B)

Figure 6. XRD spectrums of raw maghara cool (A) and the prepared activated carbon (B)

The XRD spectrums showed the crystalline structure of the carbon layers for the raw coal and activated carbon. There are two broad diffraction peaks around $2 \theta=26^{\circ}$ and $42^{\circ}$ in each spectrum, that corresponding to the planes of orientations of (002) and (100), respectively. It is generally expected that increasing the pre-carbonization temperature promotes the growth of the graphitic micro-crystallites and sharpens at the XRD peaks of the produced activated carbon compared with the raw cool as indicated from Fig.6. So, the XRD results confirm the FTIR observations to confirm that the most efficient prepared material represented as an activated carbon [14].

In order to identify the morphological structures of the raw Magahara cool and the most efficient prepared material after the chemical and thermal modification process, SEM images for both the raw cool and the produced activated carbon were investigated at Figure 7.

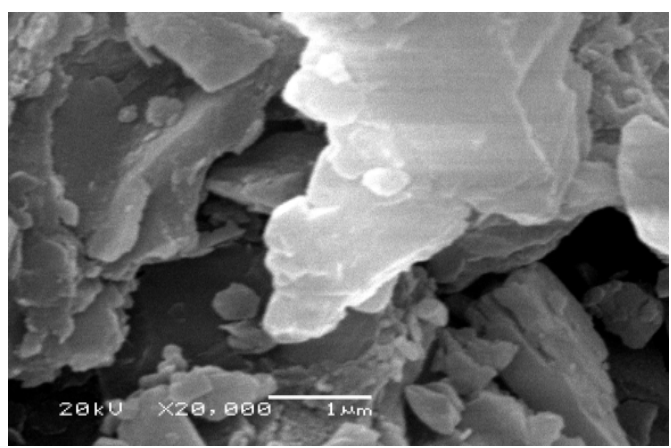

(A)

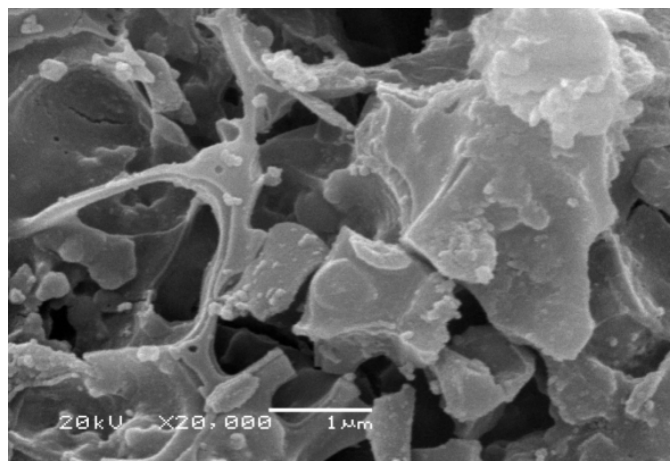

(B)

Figure 7. SEM images of raw maghara cool (A) and the prepared nano-activated carbon (B)
The surface of the primary Magahara cool was constricted, comprising mainly macro and mesopores without a deeper pore structure. Conversely, the image of the produced activated carbon displayed a well pronounced porosity, with a series of irregular cavities distributed over the surface. Moreover, noticeable nano-size spherical particles were indicated as a light spots at the material surface that represents the morphology structure of the prepared activated carbon. The average diameter of these particles was about $70 \mathrm{~nm}$. Comparison of the surface morphologies verified substantial changes occasioned by both the chemical and thermal modification process [15]. Accordingly, the most efficient prepared material is activated carbon and produced at nano-scale.

\subsection{Batch Technique for Dye Decolonization Using the Prepared Nano-Activated Carbon}

In order to optimize the methyl orange dye treatment process using the most efficient prepared nano-activated carbon, the different main factors affecting in the treatment process will be examined.

\subsubsection{Effect of Contact Time}

The effect of contact time on the percentage removal of $\mathrm{MO}$ dye onto the prepared nano-activated carbon was investigated at Fig. 8. The percentage removal of dye was rapid in the beginning and the rate of removal of MO was higher, due to the availability of more than required number of active sites on the surface of carbons and becomes slower at the later stages of contact time, due to the decreased or lesser number of active sites. The equilibrium time for the dye sorption process onto the prepared material was $120 \mathrm{~min}$.

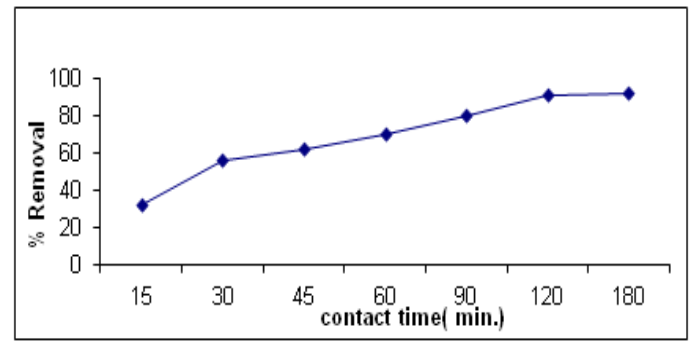

Figure 8. Effect of contact time on the MO dye sorption process onto the prepared nano-activated carbon 


\subsubsection{Effect of Mixing Speed}

Figure 9 indicated that the improvement at the mixing speed from $0 \mathrm{rpm}$ to $250 \mathrm{rpm}$ increase the percentage dye removal from $35 \%$ to $90 \%$. This enhancement in the dye sorption process was due to the increase at the diffusion rate between the dye and the particles of the nano-activated carbon.

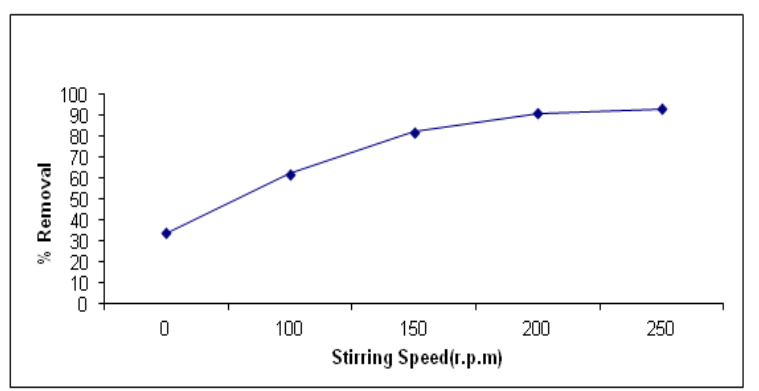

Figure 9. Effect of mixing speed on the MO dye sorption process onto the prepared nano-activated carbon

\subsubsection{Effect of Material Dosage}

The effect of dose of adsorbent on the percentage removal of MO dye was investigated at the equilibrium dye sorption time of $120 \mathrm{~min}$ and the maximum agitation speed of $250 \mathrm{rpm}$ and the results shown at Fig. 10.The percentage removal of MO increased with the increase in dose of the prepared nano-activated carbon. These results may be due to the increase in availability of surface active sites available for dye hosting onto the adsorbent material [16]. Moreover, it was indicated from the figure that the optimum dosage from the prepared nano-activated carbon was recorded at $0.25 \mathrm{~g} / \mathrm{L}$. where after this dosage the increase at the percentage dye removal is not detectable compared with the increment at the material dosage.

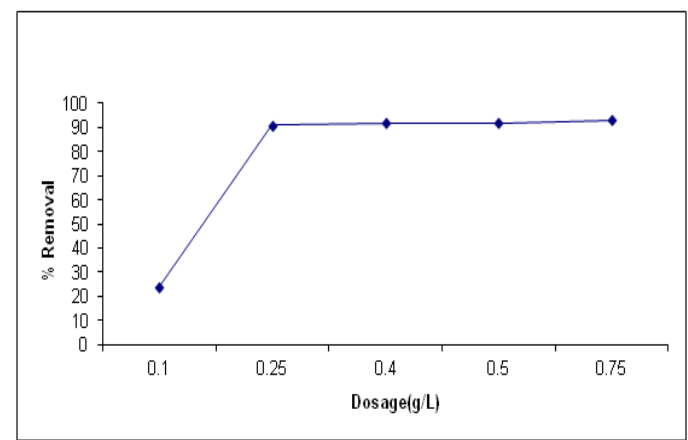

Figure 10. Effect of material dosage on the MO dye sorption process onto the prepared nano-activated carbon

\subsubsection{Effect of Initial Dye Concentration}

The effect of initial methyl orange concentration (10 ppm-150 ppm) on the removal efficiency using the predetermined optimum amount from the prepared nano-activated carbon of $0.25 \mathrm{~g}$ was showed in Fig. 11. As seen from results, the sorption yield of dye was decreased with increasing the initial dye concentration over the studied range especially for the higher studied dye concentrations above 50 $\mathrm{ppm}$. Where the removal efficiency at $120 \mathrm{~min}$ decreased from $92.7 \%$ to $50.5 \%$ as the MO dye concentration increased from
$10 \mathrm{ppm}$ to $150 \mathrm{ppm}$. This results is owing to the lack occur at the available active sites for the dye sorption onto the prepared nano-activated carbon at high initial dye concentration [17].

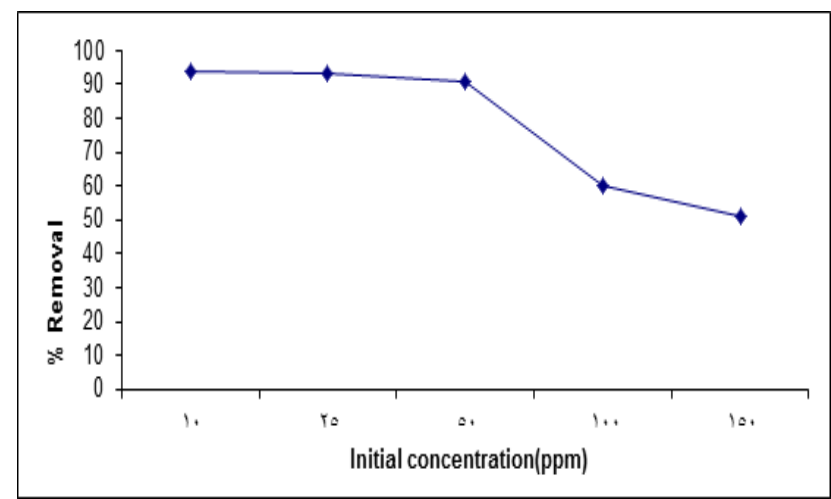

Figure 11. Effect of initial dye concentration on the MO dye sorption process onto the prepared nano-activated carbon

\subsubsection{Effect of Solution pH}

Solution $\mathrm{pH}$ affects adsorption by regulating the adsorbents surface charge as well as degree of ionization of adsorbates present in the solution. The effect of $\mathrm{pH}$ was conducted varying the $\mathrm{pH}$ of dye solutions from 2 to 12 with an initial concentration of $10 \mathrm{mg} / \mathrm{L}$, as shown in Fig. 12. A significant enhancement was noticeable at the dye removal onto the prepared nano-activated carbon at $\mathrm{pH}$ value of 7 . Lower adsorption at strong acidic $\mathrm{pH}$ is due to the protonation of $\mathrm{MO}$ and high mobility oh $\mathrm{H} 3 \mathrm{O}+$ ions competing with the dye ions for the adsorption sites [16]. At higher $\mathrm{pH}$, the nano-activated carbon may become negatively charged and the formation of electric double layer changes its polarity, consequently dye uptake decreases.

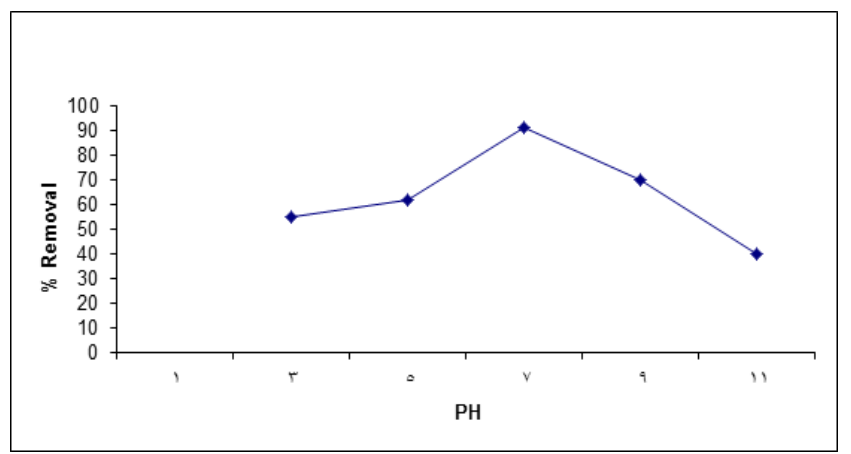

Figure 12. Effect of solution $\mathrm{pH}$ on the MO dye sorption process onto the prepared nano-activated carbon

\section{Conclusion}

Nano-activated carbon was successfully prepared from waste carbon source of Maghara cool presents at the Sinai Desert in Egypt using simple chemical and thermal modification process. It was evident from scanning electron microscopic analysis that the external surface of the prepared material after the chemical and thermal treatment that it had large cavities compared with the raw cool and produced with high porosity. Both XRD and FTIR confirm the chemical and 
crystalline structure of the prepared nano-activated carbon. The optimum treatment conditions that attain the most efficient prepared nano-activated carbon material was recorded through the alkaline chemical treatment of the raw cool using potassium hydroxide followed by carbonization the resultant powder at $600^{\circ} \mathrm{C}$ for $90 \mathrm{~min}$. the different parameters affecting the methyl dye removal onto the prepared nano-activated carbon using the batch technique was optimized. The equilibrium dye sorption time was recorded at 120 min. the optimum material dosage the record $92.4 \%$ dye removal within the equilibrium time was recorded at $0.25 \mathrm{~g} / \mathrm{L}$. the increment and decrement at the $\mathrm{pH}$ solution value around 7 declines the dye sorption process onto the prepared activated carbon.

\section{References}

[1] K. Kadirvelu, M. Kavipriya, C. Karthika, M. Radhika, N. Vennilamani, and S. Pattabhi, "Utilization of various agricultural wastes for activated carbon preparation and application for the removal of dyes and metal ions from aqueous solutions", Bioresour. Technol., vol. 87, pp. 129-132, 2003.

[2] S. Rajeswari, C. Namasivayam, and K. Kadirvelu, "Orange peel as an adsorbent in the removal of acid violet 17 (acid dye) from aqueous solutions", Waste Management, vol. 21, pp. 105-110, 2001.

[3] G. McKay, "Adsorption of dyestuffs from aqueous solutions with activated carbon, part I, equilibrium and batch contact time studies", J Chem Technol Biotechnol, vol. 32, pp.759-72, 1982.

[4] G. McKay, "Waste colour removal from textile effluents.Am Dyestuff Rep", vol. 68, pp. 29-34, 1979.

[5] P. Nigarn, L. Banat, D. Singh, and R.Marchant, " Microbial process for decolourisation of textile effluents containing azo, diazo and reactive dyes", Process Biochem, vol. 31, pp. 435-42, 1996.

[6] W. Weber, "Physico-Chemical Methods of Treatment of Water and Wastewater", John Wiley andSons Inc., 1978.
[7] B. Singh, and N. Rawat, "Comparative sorption equilibrium studies of toxic phenols on fly ash and impregnated fly ash", J Chem Technol Biotechnol., vol. 61, pp. 307-17, 1994.

[8] G. McKay, G. Prasad, and P. Mowli, "Equilibrium studies for the adsorption of dyestuff from aqueous solutions by low cost materials", Water Air Soil Pollution, vol.29, pp. 273-83, 1986.

[9] S. Khare, K. Panday, R. Srivastava, and V. Singh, "Removal of Victoria blue from aqueous solution by fly ash", J Chem Technol Biotechnol., vol. 38, pp. 99-104, 1987.

[10] V. Hernández-Montoya, D.Mendoza-Castillo, A. Bonilla-Petriciolet, M. Montes-Morán, and M. Pérez-Cruz, "Role of the pericarp of Carya illinoinensis as biosorbent and as precursor of activated carbon for the removal of lead and acid blue 25in aqueous solutions", Journal of Analytical and Applied Pyrolysis, vol. 92, pp. 143-151, 2011.

[11] H. Baioumy, "Mineralogical and Geochemical Characterization of the Jurassic Coal from Egypt", Journal of African Earth Sciences, vol. 54, pp. 75-84, 2009.

[12] A. Melegy, and S. Salman, "Petrological and environmental geochemical studies on the abandoned Maghara coal mine", Geolines, vol. 22, pp. 44-51, 2009.

[13] H. Deng, G. Li, H. Yang, J. Tanga, and J. Tang, "Preparation of activated carbons from cotton stalk by microwave assisted $\mathrm{KOH}$ and $\mathrm{K} 2 \mathrm{CO} 3$ activation", Chemical Engineering Journal ,vol. 163, pp. 373-381, 2010.

[14] P. Chingombe, B. Saha, , and R. Wakeman, "Surface modification and characterization of a coal-based activated carbon", Carbon, vol. 43, pp. 3132-3143, 2005.

[15] R. Ubago-Pérez, F. Carrasco-Marín, D. Fairén-Jiménez, C. Moreno-Castilla, "Granular and monolithic activated carbons from KOH-activation of olive stones", Microporous and Mesoporous Materials, vol. 92, pp. 64-70, 2006.

[16] K.Y. Foo, B.H. Hameed, "Mesoporous activated carbon from wood sawdust by $\mathrm{K} 2 \mathrm{CO} 3$ activation using microwave heating", Bioresource Technology, vol. 111, pp. 425-432, 2012.

[17] M. Elkady, M. Mahmoud, H. Abd-El-Rahman, "Kinetic Approach for Cadmium Sorption using Microwave Synthesized Nano-Hydroxyapatite", journal of non-crystalline solids, vol 357, pp. 1118-1129, 2011. 